\title{
Medical History End Relative to Reference Period
}

National Cancer Institute

\section{Source}

National Cancer Institute. Medical History End Relative to Reference Period. NCI

Thesaurus. Code C83331.

A characterization of the relationship of an medical history conclusion point in time to a reference point in time. 